Gut, 1969, 10, 963-972

\title{
Bacteria, bile, and the small bowel
}

\author{
SHERWOOD L. GORBACH ${ }^{1}$ AND SOAD TABAQCHALI ${ }^{2}$ \\ From the Department of Microbiology and the MRC Intestinal Malabsorption Research Group, \\ Department of Medicine, Royal Postgraduate Medical School, London
}

SUMMARY Microbial populations of the small bowel and bile salt metabolism were studied in 15 patients with lesions of the stomach and small intestine. These types of microorganism could be correlated with the site and extent of stasis in the small bowel and the presence of a normally functioning stomach. The presence of obligate anaerobes (bacteroides) and free bile acids could be correlated with areas of stagnation. When these abnormalities were detected throughout the small bowel, steatorrhoea was also noted. However, bacteroides and free bile acids in localized regions of either proximal or distal small bowel were generally associated with normal faecal fat excretion. Vitamin $B_{12}$ malabsorption appeared to be related to the total number of bacteria colonizing the small bowel rather than to any specific type of microorganisms.

The effect of antibiotics on intestinal function and bacteriology was studied in three patients. In one patient, the broad-spectrum antibiotic tetracycline was effective in eradicating an abnormal bacterial flora. In the other two, lincomycin, which is specifically effective in eradicating the anaerobic flora, restored intestinal function to normal.

Under normal circumstances the lumen of the upper gastrointestinal tract in man contains low concentrations (less than $10^{3}$ per $\mathrm{ml}$ ) of predominantly Grampositive microorganisms (Van der Reis, 1925; Gorbach, Plaut, Nahas, Weinstein, Spanknebel, and Levitan, 1967b). Anaerobic lactobacilli (bifidobacterium) and Gram-negative organisms, such as coliform and bacteroides, are usually confined to the large bowel, although the distal ileum may also contain such bacteria, possibly derived by retrograde flow from the caecum. These microorganisms, however, are not normally found in the stomach and upper small intestine of healthy individuals.

A luxuriant and abnormal intestinal bacterial flora may develop in association with certain diseases of the stomach and small intestine. Faecal-type microorganisms may colonize the upper small intestine in patients with gastrectomy, jejunal diverticulosis, blind loops, strictures, resections, and fistulae (Goldstein, Wirts, and Josephs, 1962; Wirts and Goldstein, 1963; Donaldson, 1964; Paulk and Farrar, 1964; Dellipiani and Girdwood, 1964; Tabaqchali and Booth, 1966; Tabaqchali and Booth, 1967). These bacteria may be no more than benign

${ }^{1}$ Dr Gorbach was the recipient of training grant 5 TIAI-246, Institute of Allergy and Infectious Disease, National Institute of Health, United States Public Health Service. Now at the Medical Centre, University of Illinois, Chicago, Illinois, USA.

${ }^{2}$ Address requests for reprints to: Dr S. Tabaqchali, Royal Postgraduate Medical School, London, W.12, England. commensals but under certain circumstances they may cause malabsorption of fat and vitamin $\mathrm{B}_{12}$ and interfere with the metabolism of other vitamins and of dietary protein: this situation has been termed the 'stagnant loop syndrome'.

The purpose of this investigation was to study the microflora of the gastrointestinal tract in a variety of disorders of the small intestine. Although previous workers have studied the bacterial flora in the jejunum of patients with the stagnant loop syndrome, little or no data are available on the microbial population at different levels of the alimentary tract. Where possible samples of intestinal fluid were therefore obtained by intubation at different levels of the small intestine as described by Gorbach and his colleagues (Gorbach et al, 1967b) and the relationship of the bacterial flora to the absorption of fat and vitamin $B_{12}$ was studied. Since steatorrhoea may be related to bacterial deconjugation of the bile salts within the lumen of the smal! bowel (Donaldson, 1965; Kim, Spritz, Blum, Terz, and Sherlock, 1966; Tabaqchali and Booth, 1966; Tabaqchali, Hatzioannou, and Booth, 1968), studies of the relationship between the bacteriological findings and bile salt metabolism were carried out simultaneously.

MATERIALS AND METHODS

INTUBATION OF THE GASTROINTESTINAL TRACT A double- 
lumen radioopaque polythene tube (diameter $1.8 \mathrm{~mm}$; length $400 \mathrm{~cm}$ ) with a weighted tip was passed perorally under fluoroscopic control. The distance between the two openings at the distal end of the tube was $50 \mathrm{~cm}$. Specimens were obtained from the stomach and multiple sites in the small bowel as previously described (Gorbach et al, 1967b). All samples were obtained without flushing the tube.

MICROBIAL TECHNIQUES Specimens were taken to the laboratory and were dispensed in bacteriological media within two to three hours of collection. One $\mathrm{ml}$ of the sample was thoroughly mixed with $9 \mathrm{ml}$ of sterile saline and 10 -fold tube dilutions were carried to $10^{-9}$. Earlier studies had compared the use of saline diluent with an anaerobic protein-enriched broth (thioglycollate broth. Oxoid) and no significant differences were found. Of the appropriate dilutions, $\mathbf{0} \cdot 1 \mathrm{ml}$ was spread over the surfaces of the following media: blood agar (aerobic and anaerobic), blood agar with $25 \mu \mathrm{g} / \mathrm{ml}$ neomycin (aerobic and anaerobic), MacConkey (Oxoid), Mitis-Salivarius agar (Difco), mannitol salt agar (Oxoid), and Naglarneomycin agar (anaerobic). Pour plates with $1 \mathrm{ml}$ inocula were used for Rogosa SL agar (aerobic and anaerobic, Difco) and Sabouraud agar (Oxoid) with chloramphenicol. Coliforms were counted on MacConkey plates; representative lactose and non-lactose fermenting colonies were subcultured for specification by biochemical characteristics.

Special measures were employed to achieve anaerobic conditions. Culture plates were placed in a stainless steel anaerobic jar (Baird and Tatlock, London), containing a 'cold catalyst'. An oxygen scavenger composed of steel wool impregnated with copper sulphate was also placed in each jar. The container was evacuated and flushed twice with $90 \%$ hydrogen-10\% $\mathrm{CO}_{2}$ and then remained unopened for the total period of incubation. Blood agar plates (with and without neomycin) were incubated anaerobically at $37^{\circ} \mathrm{C}$ for five days. The presence of bacteroides was confirmed by Gram stain and subculture. Non-sporulating, Gram-negative rods which would not grow aerobically were classified as bacteroides.

Lactobacilli were identified in Rogosa SL agar after three days of aerobic and anaerobic growth. Lecithinasepositive clostridia showed typical colony formation on Naglar medium after 24 to 48 hours of anaerobic incubation.

The numbers of specific microorganisms per millilitre of intestinal fluid are expressed as the logarithim to the base of 10 of the mean colony counts from plates containing 10-1,000 organisms. Sampling error and biological variation in the techniques was approximately 1.0-1.5 log (Gorbach, Nahas, Lerner, and Weinstein, 1967a).

INTESTINAL FUNCTION STUDIES Faecal fat excretion was measured on two or more consecutive three-day balance periods following a five-day equilibrium period. The diet contained $50-100 \mathrm{~g}$ of fat daily. Chromium sesquioxide was given regularly and used as an intestinal marker (Whitby and Lang, 1960). The faecal fat excretion was determined by the method of Van der Kamer (Van de Kamer, Bokkel Huinink, and Weyers, 1949). Control

TABLE I

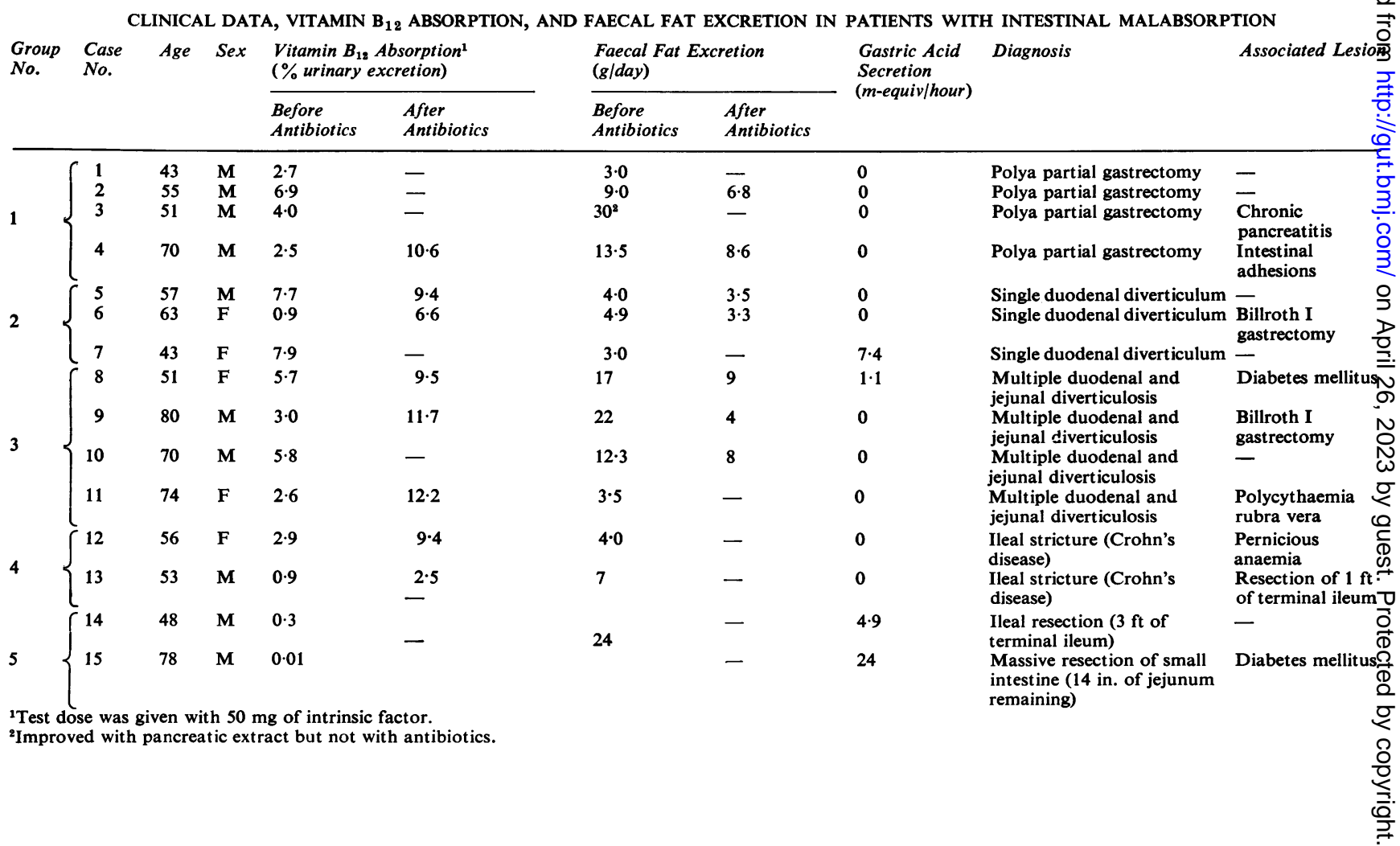


subjects excreted less than $6 \mathrm{~g}$ of fat per day with dietary intakes of up to $150 \mathrm{~g}$ of fat.

Vitamin $\mathbf{B}_{12}$ absorption was measured using the Schilling technique. The oral test dose was $1 \mu \mathrm{g}$ of ${ }^{58} \mathrm{Co}$-labelled vitamin $\mathbf{B}_{12}$. This was given either alone or with $50 \mathrm{mg}$ of intrinsic factor (Lederle Laboratories Inc). Normal values are greater than $10 \%$ of dose excreted in 24-hour urine. In some instances studies were repeated after treatment with oral antibiotics (either tetracycline or lincomycin).

THIN-LAYER CHROMATOGRAPHY OF BILE ACIDS Of freshly thawed whole intestinal fluid, $20 \mu \mathrm{l}$ was spotted on to Kieselgel $G$ thin-layer plates $(0.25 \mathrm{~mm}$ in thickness). The conjugated and free bile acids were separated by means of the solvent systems described by Hofmann and Eneroth (Hofmann, 1962; Eneroth, 1963) and were identified by comparing their mobility with that of known markers, and by their colour reactions after spraying with $15 \%$ phosphomolybdic acid in ethanol (Hofmann, 1962 ) or with $30 \%$ sulphuric acid (Eneroth, 1963). Using this method amounts greater than $3 \mu \mathrm{g}$ of bile acids can be detected.

Gastric acidity was measured using the augmented histamine test.

\section{PATIENTS STUDIED}

Fifteen patients with disorders of the stomach and small intestine were studied (Table I). Four patients had a Polya partial gastrectomy; one of these patients had chronic pancreatitis and one other had multiple adhesions involving the ileum. Seven patients had diverticula of the proximal small intestine; three had a single duodenal diverticulum and the other four had multiple jejunal diverticulosis. Two patients had lesions of the distal small intestine and two others had undergone distal small intestinal resections.

\section{RESULTS}

DISTRIBUTION OF BACTERIA IN THE LUMEN OF THE SMALL INTESTINE The results are set out in some detail for each group of patients studied.

Polya partial gastrectomy The numbers of bacteria cultured per millilitre of intestinal fluid obtained at different levels of the small intestine in the four patients with Polya partial gastrectomy are illustrated in Figure 1, which shows the results for coliforms, bacteroides, streptococci, staphylococci, clostridia and fungi, aerobic and anaerobic lactobacilli.

In these four patients, large numbers of coliforms $\left(10^{5}\right.$ to $10^{9}$ per $\left.\mathrm{ml}\right)$ were found in all specimens aspirated from the gastric remnants and at the various levels of the small intestine (Fig. 1). In

MICROBIAL FLORA IN PATIENTS WITH POLYA PARTIAL GASTRECTOMY

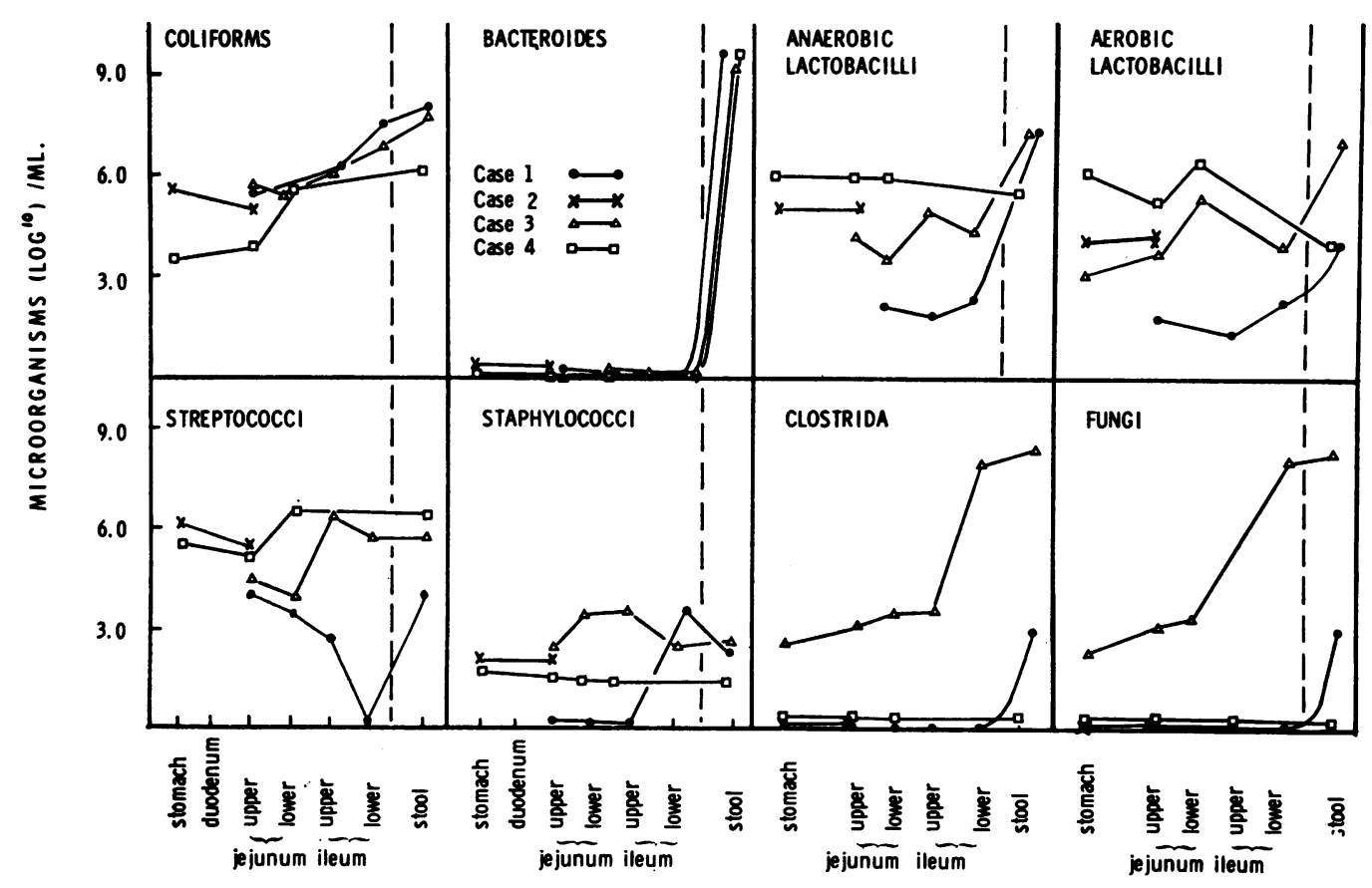

FIG. 1. The microbial flora of the gastrointestinal tract in patients with polya partial gastrectomy. 
MICROBIAL FLORA IN PATIENTS WITH SINGLE DUODENAL DIVERTICULUM

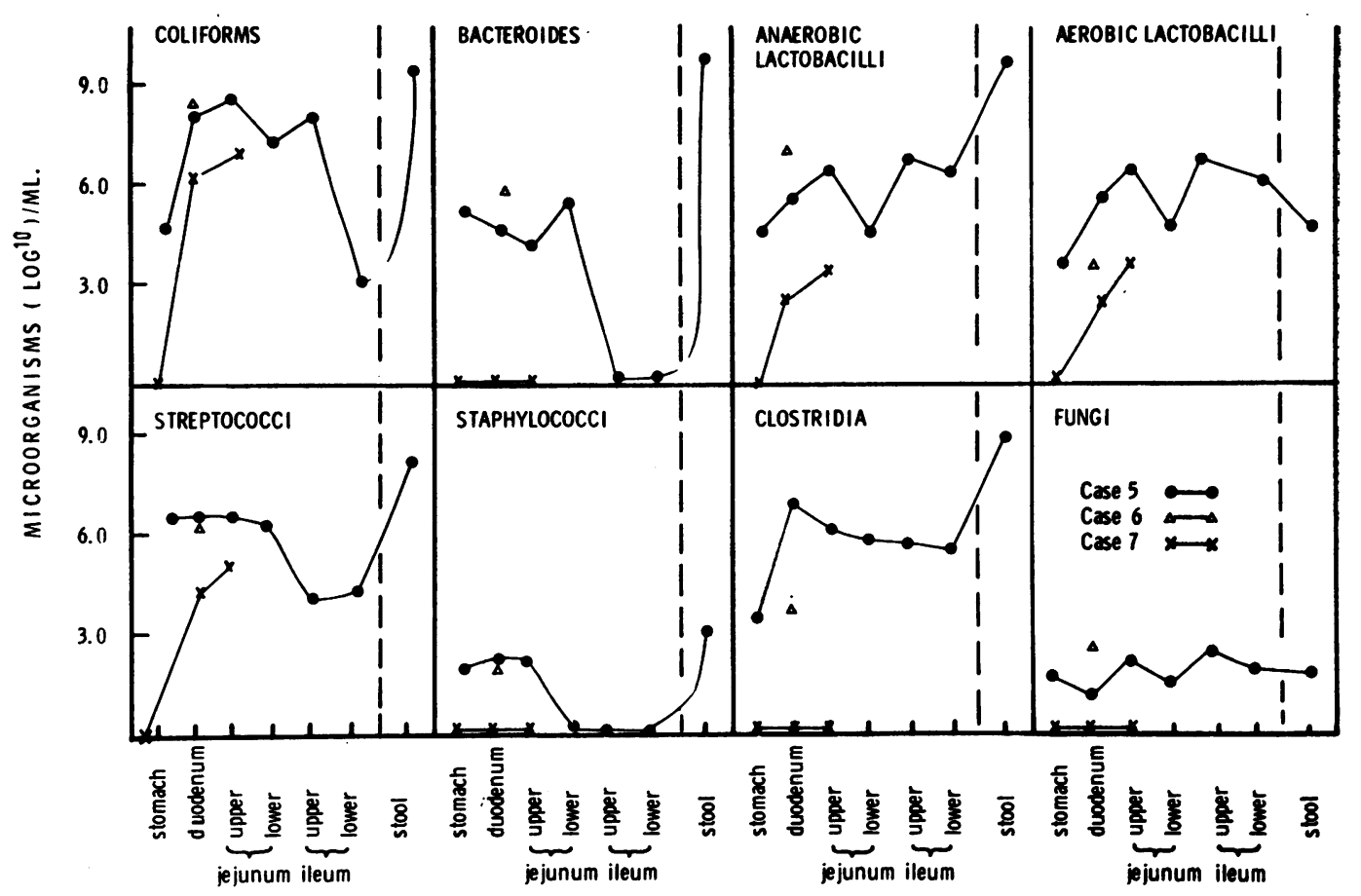

FIG. 2. The microbial flora of the gastrointestinal tract in patients with single duodenal diverticulum.

lesser concentrations, there were also streptococci, lactobacilli, and, in one patient (case 3), clostridia and fungi. No bacteroides were present in any of the samples, however, although there were high concentrations in the stools.

Single duodenal diverticulum The results in the three patients with a single duodenal diverticulum are shown in Figure 2. The first of these patients (case 5) had achlorhydria. In this patient, coliforms, aerobic and anaerobic lactobacilli, streptococci and clostridia, were present in relatively high concentrations throughout the small intestine. Bacteroides were also present in the samples aspirated from stomach, duodenum, and jejunum, but were strikingly absent from the ileal samples and in these samples the concentration of coliforms was lower (Fig. 2). In a second patient (case 6) in whom there was also achlorhydria, a single sample taken from the duodenum revealed bacteroides in similar concentrations as well as coliforms, streptococci, and anaerobic lactobacilli.

The third patient (case 7) had normal gastric acidity. In this patient the findings were different. No microorganisms were cultured from the stomach and whereas coliforms and streptococci were found in samples obtained from the duodenum and jejunum, no bacteroides were present at any level (Fig. 2).

Multiple jejunal diverticulosis The findings in the four patients with multiple jejunal diverticulosis are shown in Figure 3. In three of these patients (cases 8,9 , and 10), coliforms, bacteroides, aerobic and anaerobic lactobacilli, and streptococci were cultured from all levels of the small intestine in relatively high concentrations. In the fourth patient (case 11), however, the bacteriological findings contrasted with those in the other three patients. Although coliforms, streptococci, and anaerobic lactobacilli were present in the stomach and upper small bowel, bacteroides were restricted to the ileum in this patient.

Lesions of the distal small intestine Two patients (cases 12 and 13) with localized stricture of the terminal ileum due to regional enteritis were studied. The bacteriological findings at different levels of the small intestine are shown in Figure 4. Although coliforms, anaerobic lactobacilli and streptococci were present throughout the small intestine in these patients, the most striking feature was the absence of bacteroides from the upper intestine and their appearance in the area of stasis in the ileum (Fig. 4). 
Bacteria, bile, and the small bowel

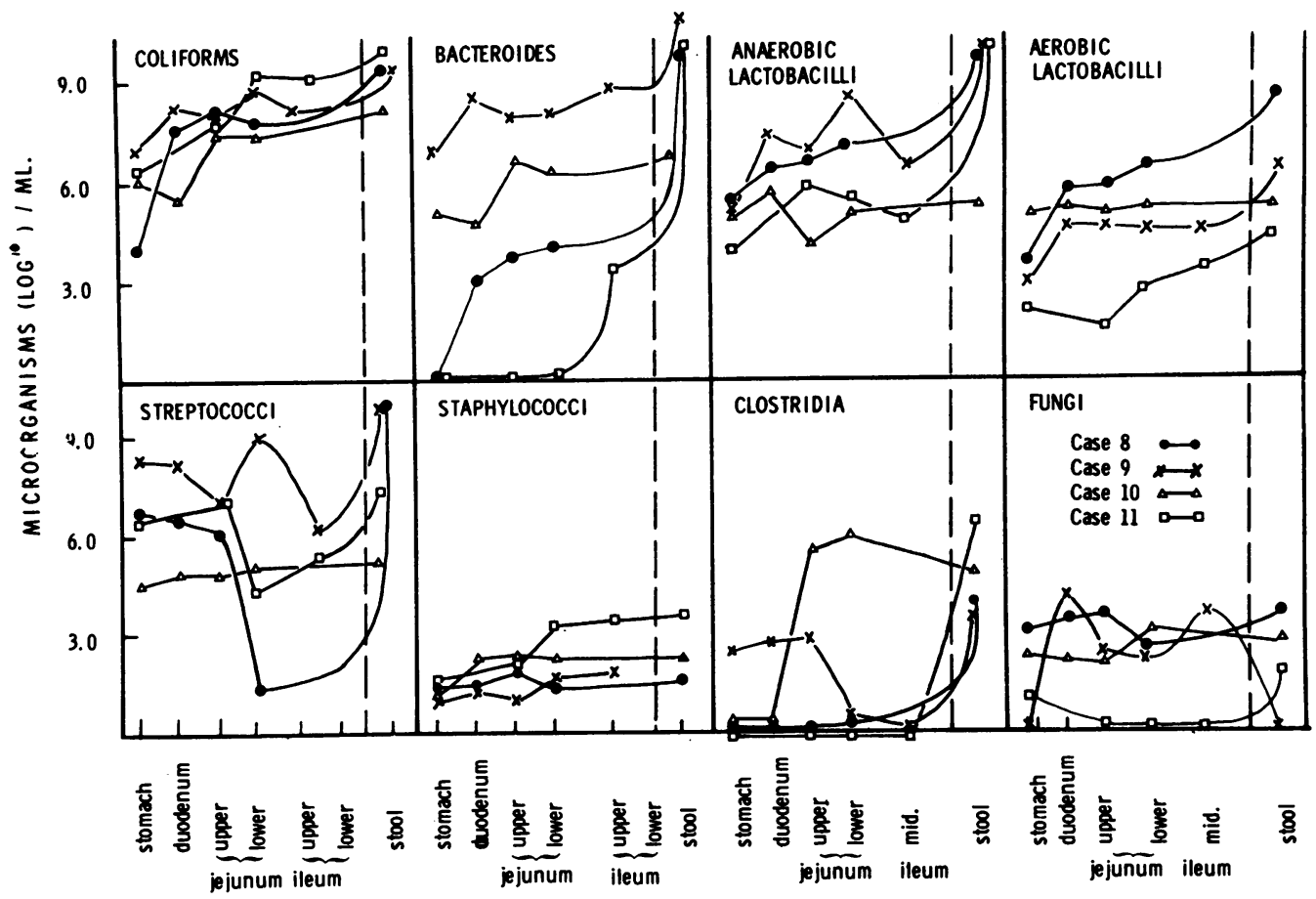

FIG. 3. The microbial flora of the gastrointestinal tract in patients with multiple duodenal and jejunal diverticulosis.

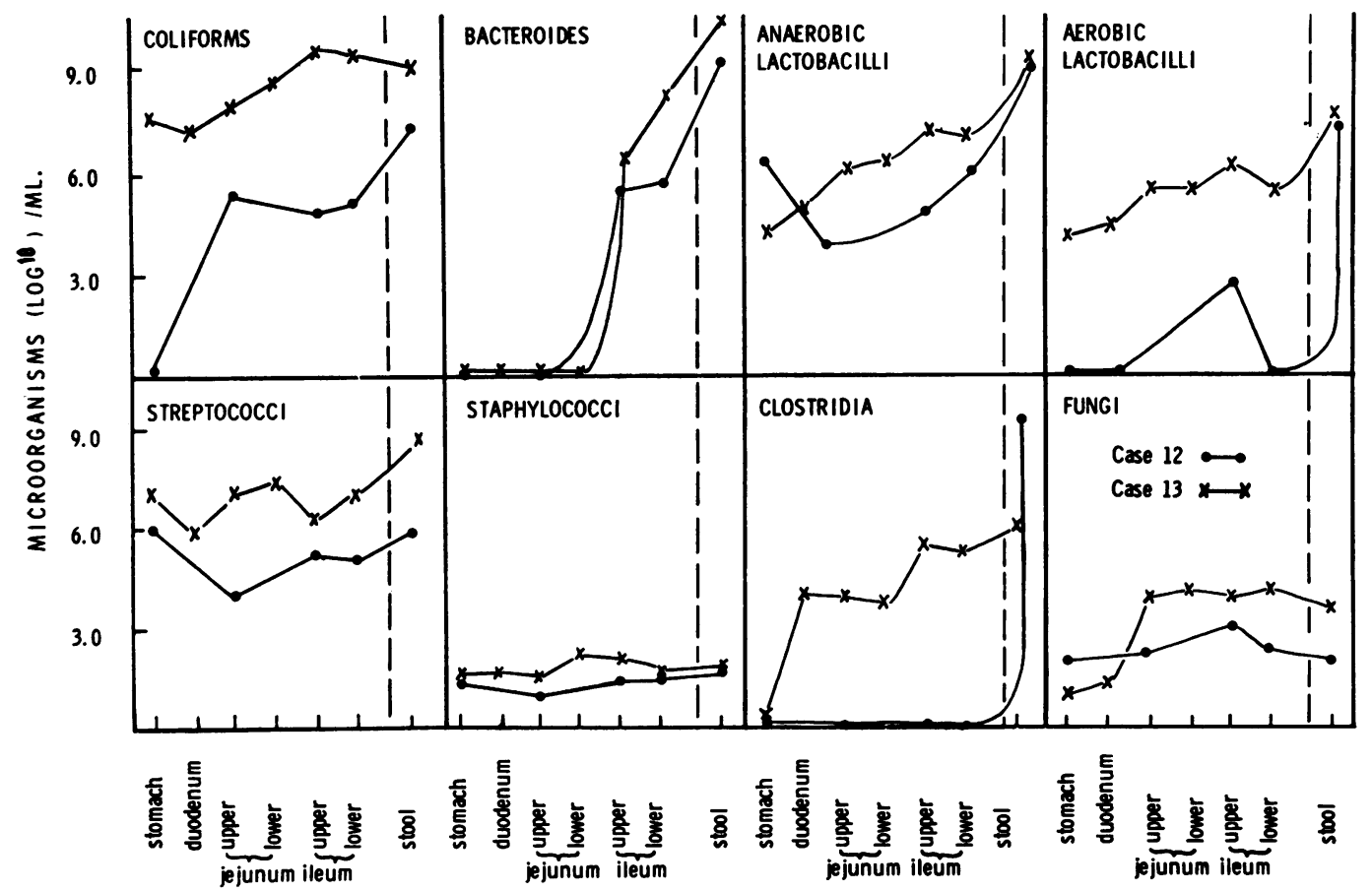

FIG. 4. The microbial flora of the gastrointestinal tract in patients with distal intestinal strictures. 


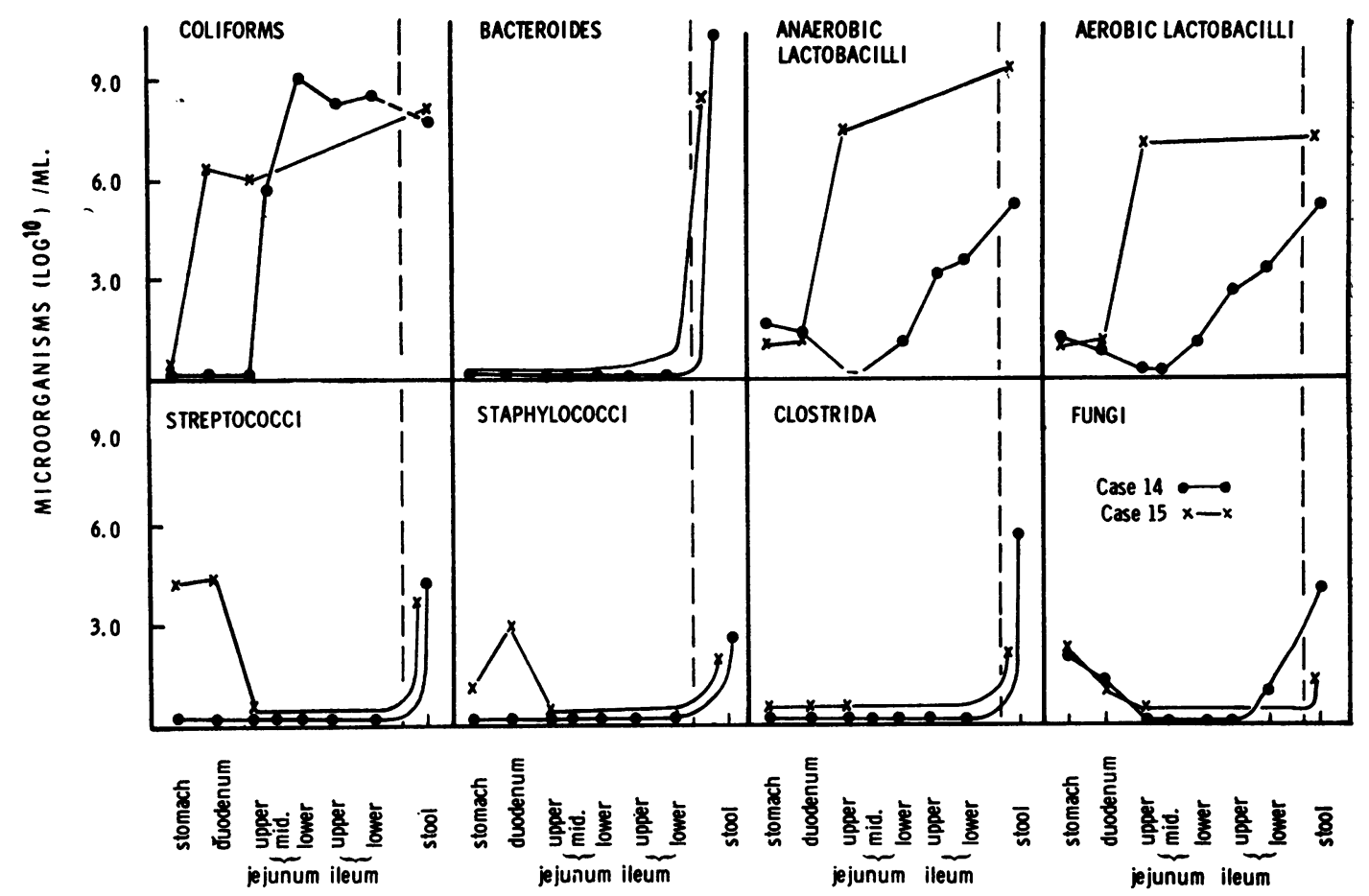

FIG. 5. The microbial flora of the gastrointestinal tract in two patients with distal intestinal resection.

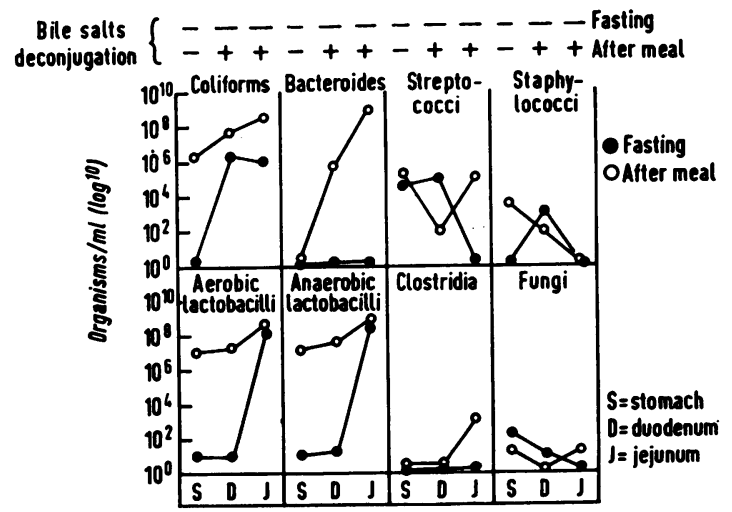

FIG. 6. The effect of feeding on the microbial flora and bile salt metabolism in a patient with massive distal intestinal resection (case 15). Plus and minus represent the presence or absence of bile salt deconjugation respectively in the intestinal aspirates.
Resection of the distal small intestine The results in the two patients with resection of the distal small intestine are shown in Figure 5. The first patient (case 13) had undergone resection of only $3 \mathrm{ft}$ of the distal ileum. In this patient coliforms, and, to a lesser extent, anaerobic lactobacilli, were present in the lower jejunum and ileum but no bacteroides were cultured from the small intestinal samples. The second patient (case 15) had undergone massive resection of the small intestine following a mesenteric venous thrombosis, only 14 in. of the jejunum remaining, anastomosed end to end to the transverse colon. The patient had normal gastric acid secretion. In the fasting state coliforms were absent from the stomach but present in the duodenum and jejunum together with streptococci and anaerobic lactobacilli. No bacteroides were detected, however, in these fasting samples (Fig. 5). The studies were then repeated after a meal of hot tea and toast. The postprandial samples now yielded bacteroides as well as coliforms and other microorganisms from all three areas studied (Fig. 6). Bile salt deconjugation was present in the postprandial samples.

TYPES OF BACTERIA ASSOCIATED WITH BILE SALT DFCONJUGATION in vivo During the course of this 
TABLE II

MICROORGANISMS ASSOCIATED WITH DECONJUGATION OF BILE SALTS IN SMALL BOWEL FLUID

Isolation of Intestinal Microorganisms in Small Bowel Fluid

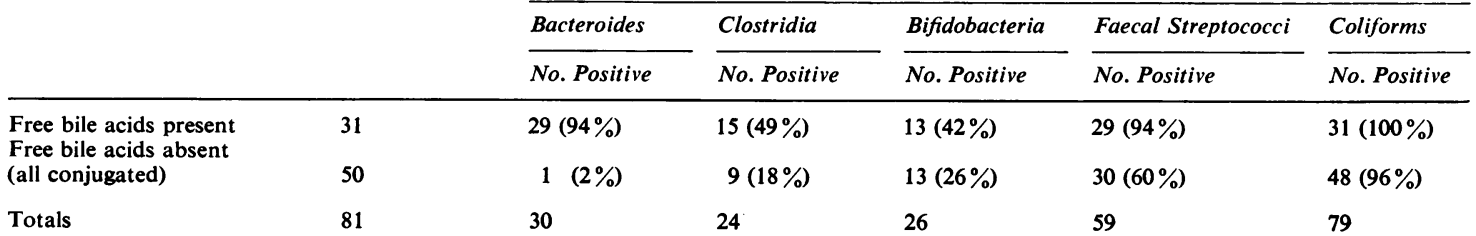

study, 81 specimens of small intestinal fluid were examined by thin-layer chromatography for evidence of bile acid deconjugation. Free bile acids (cholic chenodeoxycholic, and deoxycholic acid) were present in 31 of these samples but only conjugated bile acids were found in the remaining 50 specimens. There was a close correlation between the presence of free bile acids and the anaerobic bacteroides in the intestinal samples (Table II). Of the 31 samples in which free bile acids were found, bacteroides were present in 29. In the 50 samples without bile salt deconjugation, only one contained bacteroides. No correlation was found between the presence or absence of bile salt deconjugation and other microorganisms (Table II).

GASTRIC ACIDITY, BACTERIOLOGY, AND BILE SALTS The relationship between gastric acidity and the presence and type of bacteria in stomach, duodenum, and jejunum was studied in these 15 patients. Twelve patients had gastrectomy or achlorhydria associated with lesions in the small intestine. All but one of these patients had coliforms $\left(10^{4}-10^{8}\right.$ per $\left.\mathrm{ml}\right)$ in the stomach and upper intestine. Furthermore, those patients, who had evidence of proximal stasis in duodenal or jejunal diverticula, also had bacteroides $\left(10^{3}-10^{8}\right.$ per $\left.\mathrm{ml}\right)$ associated with bile salt deconjugation. By contrast, no coliforms were cultured from the stomach of three patients with normal gastric acid secretion and only small numbers $\left(10^{2}-10^{4}\right.$ per $\mathrm{ml}$ ) of streptococci and anaerobic lactobacilli were found in the gastric samples. The bacterial flora of the proximal small intestine was also different in these patients. The duodenum and upper jejunum contained coliforms $\left(10^{6}-10^{7}\right)$ but no bacteroides were present and there was no evidence of bile salt deconjugation.

EFFECTS OF ANTIBIOTIC TREATMENT ON BACTERIAL FLORA AND INTESTINAL FUNCTION The concentrations of microorganisms cultured at different levels of the small intestine in three patients before and after treatment with either lincomycin $(500 \mathrm{mg}$ eight-hourly for seven days) or tetracycline ( $250 \mathrm{mg}$

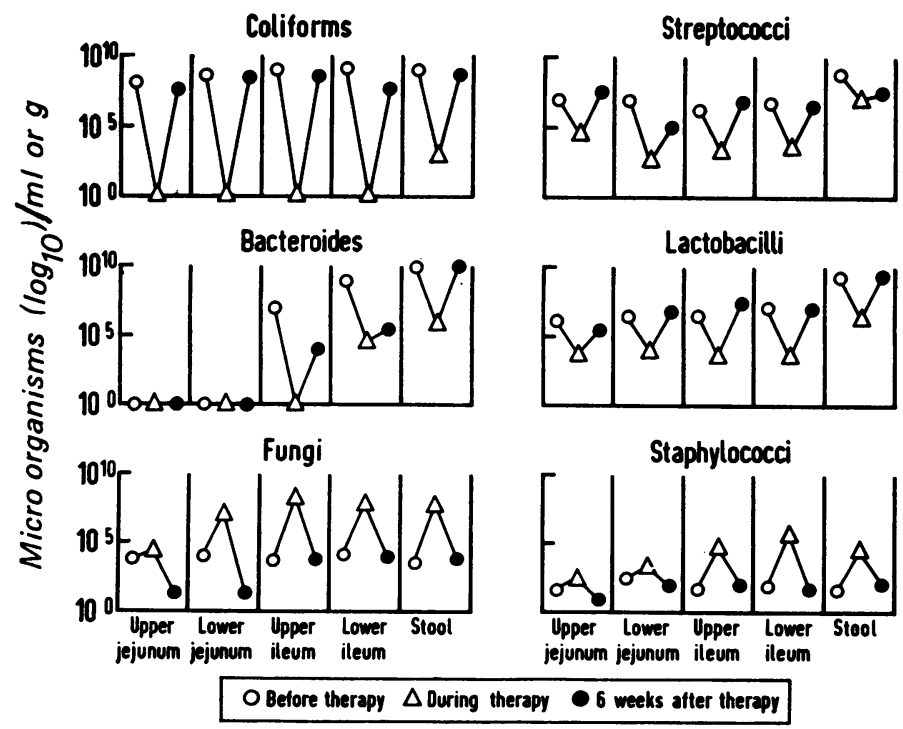

FIG. 7. The effect of antibiotics on the microbial flora of a patient with distal intestinal stricture (case 13). 
TABLE III

EFFECT OF LINCOMYCIN ON THE MICROBIAL FLORA AND BILE SALT METABOLISM

\begin{tabular}{|c|c|c|c|c|c|c|c|c|}
\hline \multirow[t]{3}{*}{ Case No. } & \multirow[t]{3}{*}{ Antibiotic Used } & \multirow[t]{3}{*}{ Site of Sampling } & \multicolumn{6}{|c|}{ Microorganisms Isolated $(\log 10)(\mathrm{ml}$ or $\mathrm{g})$} \\
\hline & & & \multicolumn{2}{|c|}{ Coliforms } & \multicolumn{2}{|c|}{ Bacteroides } & \multicolumn{2}{|c|}{ Streptococci } \\
\hline & & & Before & After & Before & After & Before & After \\
\hline \multirow[t]{2}{*}{5} & \multirow[t]{2}{*}{$\begin{array}{l}\text { Lincomycin } 500 \mathrm{mg} \\
8 \text { hourly }\end{array}$} & $\begin{array}{l}\text { Stomach } \\
\text { Upper jejunum } \\
\text { Lower jejunum } \\
\text { Upper ileum }\end{array}$ & $\begin{array}{l}4.9 \mathrm{~A} \\
8 \cdot 7 \mathrm{~A} \\
7 \cdot 2 \mathrm{~A} \\
8 \cdot 2 \mathrm{~A} \\
7 \cdot 8 \mathrm{P}\end{array}$ & $\begin{array}{l}7 \cdot 8 \mathrm{P} \\
8 \cdot 5 \mathrm{P} \\
8 \cdot 0 \mathrm{~A} \\
8 \cdot 7 \mathrm{~A} \\
8 \cdot 7 \mathrm{P}\end{array}$ & $\begin{array}{l}5 \cdot 3 \\
4 \cdot 0 \\
5 \cdot 6 \\
0\end{array}$ & $\begin{array}{l}0 \\
0 \\
0 \\
0\end{array}$ & $\begin{array}{l}6 \cdot 5 \\
6 \cdot 5 \\
6 \cdot 3 \\
4 \cdot 0\end{array}$ & $\begin{array}{l}6 \cdot 4 \\
6 \cdot 0 \\
5 \cdot 7 \\
6 \cdot 5\end{array}$ \\
\hline & & Stool & $\begin{array}{l}6.5 \mathrm{P} \\
9.5 \mathrm{~A}\end{array}$ & $\begin{array}{l}8 \cdot 5 \mathrm{P} \\
8 \cdot 3 \mathrm{~A} \\
7 \cdot 1 \mathrm{P} \\
8 \cdot 2 \mathrm{E}\end{array}$ & $9 \cdot 8$ & $<10^{3}$ & $8 \cdot 5$ & $9 \cdot 0$ \\
\hline \multirow[t]{3}{*}{9} & \multirow[t]{3}{*}{$\begin{array}{l}\text { Lincomycin } 500 \mathrm{mg} \\
8 \text { hourly }\end{array}$} & Duodenum & $7 \cdot 2 \mathrm{~A}$ & $\begin{array}{l}7 \cdot 6 \mathrm{~A} \\
8 \cdot 3 \mathrm{E}\end{array}$ & $7 \cdot 1$ & 0 & $8 \cdot 5$ & $6 \cdot 5$ \\
\hline & & Upper jejunum & $8 \cdot 3 \mathrm{~A}$ & $\begin{array}{l}7 \cdot 6 \mathrm{~A} \\
8 \cdot 7 \mathrm{E}\end{array}$ & $7 \cdot 6$ & 0 & $7 \cdot 6$ & $6 \cdot 0$ \\
\hline & & Stool & $9 \cdot 5 \mathrm{~A}$ & $9 \cdot 3 \mathrm{~A}$ & $11 \cdot 4$ & $<10^{4}$ & $10 \cdot 0$ & $5 \cdot 8$ \\
\hline
\end{tabular}

six-hourly for seven days) are set out in Table III and Figure 7.

The first patient (case 5), who had a single duodenal diverticulum and achlorhydria, was treated with lincomycin. Although there was little change in the concentrations of coliforms, streptococci, and lactobacilli, there was a dramatic fall in the bacteroides and clostridia which were no longer present after antibiotic treatment. At the same time free bile acids disappeared from the intestinal fluid. Faecal fat excretion, which was normal, did not change significantly nor did vitamin $\mathbf{B}_{12}$ absorption.

The second patient (case 9) had jejunal diverticulosis, achlorhydria, and extensive bacterial proliferation throughout the small intestine (Fig. 3). After treatment with lincomycin the concentrations of both bacteroides and clostridia in the jejunum fell dramatically but there was no change in the concentrations of coliforms, streptocorci, and lactobacilli. At the same time there was now no bile salt deconjugation following treatment with lincomycin, and the faecal fat excretion fell from 22 to $4 \mathrm{~g}$ daily.

The third patient (case 13 in Fig. 7) had achlorhydria and a stricture of the distal ileum. After treatment with tetracycline for seven days, there was a marked fall in the concentration of coliforms, bacteroides, streptococci, and lactobacilli at all levels of the small intestine but there was an increase in the concentrations of fungi $\left(10^{7}-10^{8}\right.$ per $\left.\mathrm{ml}\right)$ and staphylococci $\left(10^{4}-10^{5}\right.$ per $\left.\mathrm{ml}\right)$. The faecal fat fell from 7.0 to $5.0 \mathrm{~g}$ per day but vitamin $\mathrm{B}_{12}$ absorption did not change significantly. Six weeks following cessation of antibiotics, a repeat intubation study was performed as demonstrated in Figure 7. There was a general return to the pretreatment microflora. The numbers of coliforms and lactobacilli rose to former levels. The streptococci were generally increased although in the lower jejunum and stool, they were somewhat below the pretreatment values. Similarly, fungi and staphylococci fell to the numbers found before tetracycline treatment.

Two important differences were noted in the specimens from this patient obtained six weeks after treatment. Although the total number of coliforms were the same, approximately $50 \%$ were now Aerobacter aerogenes and the remainder were different biotypes of $E$. coli. No aerogenes were found in higher dilutions of pretreatment samples. Furthermore, the number of bacteroides in the ileal specimens was significantly less than in the pretreatment specimens.

\section{DISCUSSION}

Previous studies of the intestinal microflora in patients with disorders of the small intestine have emphasized that coliform microorganisms were most frequently found, and these microorganisms have often been incriminated as causing the absorption defects in the stagnant loop syndrome. It was not until 1966 that Drasar, Hill, and Shiner (1966) showed as in stools the anaerobic flora might be present in the lumen of the gut in the highest concentrations. Furthermore, on the basis of experiments in vitro, they suggested that bacteroides in particular might be responsible for the steatorrhoea through its known ability to deconjugate bile salts, a facility not possessed by coliforms.

Microbial populations of the diseased small bowel have previously been investigated by sampling the upper jejunum in fasting subjects (Goldstein et al, 1962; Wirts and Goldstein, 1963; Donaldson, 1964; Paulk and Farrar, 1964; Dellipiani and Girdwood, 1964; Tabaqchali and Booth, 1966). Although this approach has yielded useful information, the results presented in this paper demonstrate 
TABLE III-continued

EFFECT OF LINCOMYCIN ON THE MICROBIAL FLORA AND BILE SALT METABOLISM

Microorganisms Isolated (log 10) ( $\mathrm{ml}$ or $\mathrm{g})$

Bile Salt Deconjugation

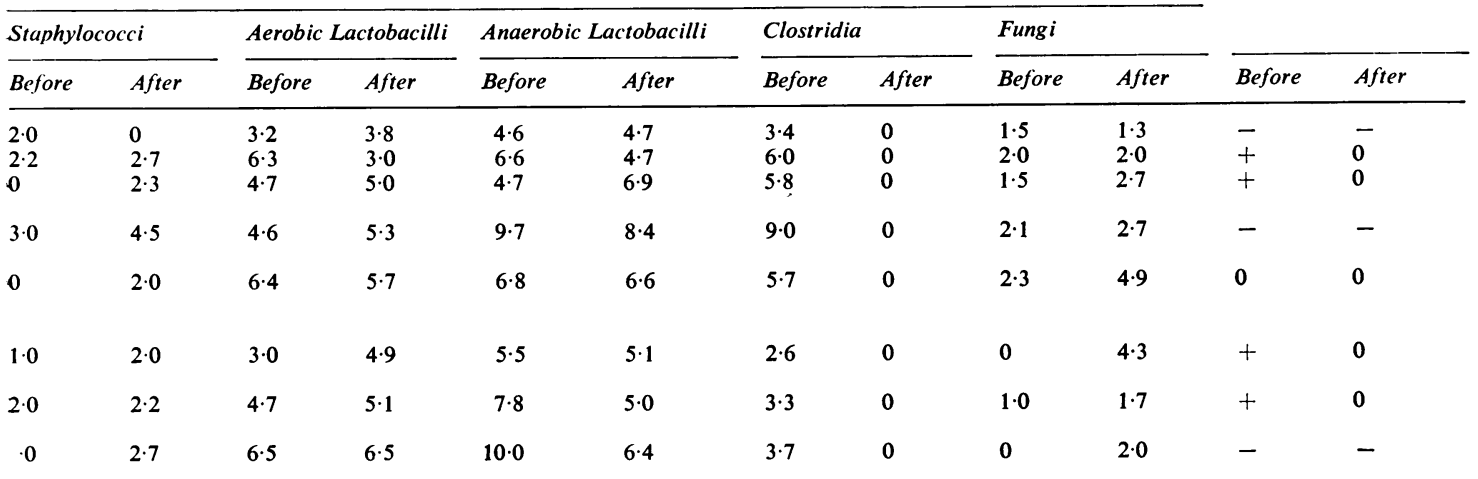

that the microflora of the small intestine is best revealed by multiple sampling at various levels since the bacterial flora in different patients may be related to the site and extent of the anatomical abnormality of the intestine. The validity of this technique has been demonstrated by comparative studies with a closed capsule (Kalser, Cohen, Arteaga, Yawn, Mayoral, Hoffert, and Frazier, 1966), and by a direct surgical approach in man (Anderson and Langford, 1958), and in experimental animals (Gorbach et al, 1967b).

The results of these studies at multiple levels of the small intestine show that although many patients had an extensive growth of microorganisms, such as coliforms and lactobacilli, throughout the small bowel irrespective of the causative lesion, the presence of anaerobic microorganisms and free bile acids was found to be related to local anatomical defects. For example, bacteroides and bile salt deconjugation generally occurred only in relation to areas of stasis. Patients with duodenal and upper jejunal diverticula might show these abnormalities in proximal sites (Figs. 2 and 3), while stagnation of the ileum was associated with bacteroides and bile salt splitting in distal regions (Fig. 4). In normal subjects or patients with uncomplicated gastric resection, microorganisms of the bacteroides group are generally absent in the small bowel, although small numbers are occasionally found in the distal ileum. It appears, therefore, that the micro-environment necessary for growth of this fastidiousanaerobe, that is, low oxidation-reduction potential, is available in areas of intestinal stasis. This requirement appears to be fulfilled in the colon or terminal ileum of normal subjects and in the stagnant area of small bowel in patients with diverticula, strictures, or blind loops.
Although a variety of intestinal microorganisms are able to deconjugate bile salts in vitro, ie, clostridia faecal streptococci, anaerobic lactobacilli, and bacteroides (Norman and Grubb,1955;Drasar et al,1966; Midtvedt and Norman, 1967; Hill and Drasar, 1968), it has been uncertain which species are responsible for this reaction in vivo. The results presented in this paper suggest that deconjugation of bile salts occurs in areas of stasis where conditions favour the growth of an anaerobic flora and that bacteroides may be the major bacterial species responsible for deconjugation. In patients with partial gastrectomy, for example, there were relatively high concentrations of coliform organisms but no bacteroides or bile salt deconjugation. In patients with ileal stricture, although coliforms and other organisms were present throughout the small intestine, bacteroides were restricted to the area of stasis in the ileum and bile salt deconjugation only occurred in the intestinal samples obtained from this region. However, the evidence for incriminating bacteroides in deconjugation of bile salts in vivo is largely circumstantial and it is possible that this microorganism may only be serving as a marker for the physicochemical environment of a stagnant area which allows the deconjugation reaction to proceed by a variety of other bacteria. The importance of bacteroides in the aetiology of the blind loop syndrome has been emphasized by Polter, Boyle, Miller, and Finegold (1968). These authors studied a single patient with jejunal diverticulosis in whom they used several antibiotics, including lincomycin, and demonstrated that malabsorption of fat and vitamin $B_{12}$ was related to the anaerobic flora in the jejunum of their patient.

The results of treatment with lincomycin reported in this paper (Table III) support the hypothesis that 
bacteroides appears to be responsible for bile salt deconjugation in such patients, since eradication of these microorganisms by lincomycin, without affecting the aerobic bacterial flora, led to a reduction in steatorrhoea and disappearance of free bile acids from the intestinal fluid. Lincomycin may, therefore, be of particular value in the treatment of patients with malabsorption due to bacterial contanination of the small bowel.

Extensive deconjugation of bile salts throughout the small bowel was associated with steatorrhoea. This correlates with quantitative bile salt studies in several patients in this series (Tabaqchali et al, 1968), which have shown that defective absorption was associated with a reduction in the level of the conjugated bile salts below the critical concentration for micellar formation. On the other hand, when deconjugation was limited to either jejunum or ileum, steatorrhoea was not present; under these circumstances there may be sufficient concentrations of conjugated bile salts to facilitate normal fat absorption even though high concentrations of free bile acids may be present (Tabaqchali et al, 1968).

Those patients with extensive bacterial deconjugation of bile salts in the small bowel and steatorrhoea are examples of the stagnant loop syndrome (cases 8 , 9, and 10). However, steatorrhoea was also observed in the absence of small bowel stasis or bile salt deconjugation. In two such patients with gastrectomy and one with pancreatic insufficiency, the concentration of conjugated bile salts was normal and defective fat absorption was apparently related to other causes. The patient with extensive distal intestinal resection (case 15), on the other hand, had a reduced concentration of conjugated bile salts in the jejunum, presumably as a result of impaired reabsorption in the ileum (Austad, Lack, and Tyor, 1967). The effect of feeding on the small bowel microflora in this patient (case 15) was striking (Fig. 6). Fasting specimens had a sparse microflora and there was no bile salt deconjugation, whereas the postprandial specimens contained large numbers of coliforms, bacteroides, and lactobacilli (Fig. 6), and free bile acids were also demonstrated. It is possible that these microorganisms had passed retrograde from the colon into the small intestine since this patient had no ileo-caecal valve. Bacterial contamination of the small intestine may, therefore, contribute to the steatorrhoea of patients with intestinal resection by causing bilesalt deconjugation.

We wish to express grateful thanks to Professor C. C. Booth for his advice and guidance in these studies. Technical assistance was provided by Mr. Josh Wright and other members of the Departments of Microbiology and Medicine, Royal Postgraduate Medical School. We are particularly grateful to Mr. Joseph Hall (case 13) for his helpful cooperation. We also thank Messrs Upjohn Ltd for their generous support of this work.

\section{REFERENCES}

Anderson, C. M., and Langford, R. F. (1958). Bacterial content of small intestine of children in health, in coeliac disease, and in fibrocystic disease of pancreas. Brit. med. J., 1, 803-806.

Austad, W. I., Lack, L., and Tyor, M. P. (1967). Importance of bile acid and of an intact distal small intestine for fat absorption. Gastroenterology, 52, 638-646.

Dellipiani, A. W., and Girdwood, E. H. (1964). Bacterial changes in the small intestine in malabsorptive states and in pernicious anaemia. Clin. Sci, 26, 359-374.

Donaldson, R. M., Jr. (1964). Normal bacterial populations of the intestine and their relation to intestinal function. New Engl. J. Med., 270, 1050-1056.

- (1965). Studies on the pathogenesis of steatorrhea in the blind loop syndrome. J. clin. Invest., 44, 1815-1825.

Drasar, B. S., Hill, M. J., and Shiner, M. (1966). The deconjugation of bile salts by human intestinal bacteria. Lancet, 1, 1237-1238.

Eneroth, P. (1963). Thin layer chromatography of bile acids. J. Lipid Res., 4, 11-16.

Goldstein, F., Wirts, C. W., and Josephs, L. (1962). The bacterial flora of the small intestine. Gastroenterology, 42, 755-756.

_, Plaut, A. G., Nahas, L., Weinstein, L., Spanknebel, G., and Levitan, R. (1967b). Studies of intestinal microflora. II. Micro-organisms of the small intestine and their relations to oral and fecal flora. Ibid., 53, 856-867.

Gorbach, S. L., Nahas, L., Lerner, P., and Weinstein, L. (1967a). Studies of intestinal microflora. I. Effects of diet, age and periodic sampling on numbers of fecal micro-organisms in man. Ibid., 53, 845-855.

Hill, M. J., and Drasar, B. S. (1968). Degradation of bile salts by human intestinal bacteria. Gut, 9, 22-27.

Hofmann, A. F. (1962). Thin layer adsorption chromatography of free and conjugated bile acids on silicic acid. J. Lipid Res., 3, 127-128.

Kalser, M. H., Cohen, R., Arteaga, I., Yawn, E., Mayoral, L., Hoffert W. R., and Frazier, D. (1966). Normal viral and bacterial flora of the human small and large intestine. New Engl. J. Med., 247, 500-505.

Kim, Y. S., Spritz, N., Blum, M., Terz, J., and Sherlock, P. (1967). The role of altered bile acid metabolism in the steatorrhoea of experimental blind loop. J. clin. Invest., 45, 956-962.

Midtvedt, T., and Norman, A. (1967). Bile acid transformations by microbial strains belonging to genera found in intestinal contents. Acta path. microbiol. scand., 71, 629-638.

Norman, A., and Grubb, A. (1955). Hydrolysis of conjugated bile acids by clostridia and enterococci. Ibid., 36, 537-547.

Paulk, E. A., Jr., and Farrar, W. E., Jr. (1964). Diverticulosis of the small intestine and megaloblastic anemia. Amer. J. Med., $37,473-480$.

Polter, D. E., Boyle, J. D., Miller, L. G., and Finegold, S. M. (1968). Anaerobic bacteria as cause of the blind loop syndrome. Gastroenterology, 54, 1148-1154.

Tabaqchali, S., and Booth, C. C. (1966). Jejunal bacteriology and bile salt metabolism in patients with intestinal malabsorption. Lancet, 2, 12-15.

- - - (1967). The Relationship of the intestinal bacterial flora to absorption. Brit. med. Bull., 23, 285-290.

_-, Hatzioannou, J., and Booth, C. C. (1968). Bile salt deconjugation and steatorrhoea in patients with the stagnant loop syndrome. Lancet, 2, 12-16.

Van de Kamer, J. H., Bokkel Huinink, H. T., and Weyers, H. A. (1949). Rapid method for determination of fat in feces. J. biol. Chem., 177, 347-355.

Van der Reis, V. (1925). Die Darmbakterien der Erwachsenen und ihre Klinische Bedeutung. Ergebn. inn. Med. Kinderheilk., 27, 77-178.

Whitby, L. G., and Lang, D. (1960). Experience with chromic oxide method of fecal marking in metabolic balance investigations on humans. J. clin. Invest., 39, 854-863.

Wirts, C. W., and Goldstein, F. (1963). Studies of the mechanism of post gastrectomy steatorrhoea. Ann. intern. Med., 58, 25-36. 